\title{
Kinetics of Slag Reduction in Silicomanganese Production
}

\author{
VINCENT CANAGUIER and MERETE TANGSTAD
}

In this study, the reduction of three silicomanganese charges prepared from industrial raw materials was investigated under isothermal conditions between $1783 \mathrm{~K}$ and $1933 \mathrm{~K}\left(1510{ }^{\circ} \mathrm{C}\right.$ and $1660{ }^{\circ} \mathrm{C}$ ). The main reactions examined are $\mathrm{MnO}$ and $\mathrm{SiO}_{2}$ slag reduction following the chemical equations $\mathrm{MnO}(\mathrm{l})+\mathrm{C}=\mathrm{Mn}(\mathrm{l})+\mathrm{CO}(\mathrm{g})$ and $\mathrm{SiO}_{2}(\mathrm{l})+2 \mathrm{C}=\mathrm{Si}(\mathrm{l})+2 \mathrm{CO}(\mathrm{g})$. The charges containing a combination of Assmang ore, Comilog ore, high-carbon FeMn slag with quartz were pre-reduced, melted to a $\mathrm{MnO}-\mathrm{SiO}_{2}-\mathrm{Al}_{2} \mathrm{O}_{3}-\mathrm{MgO}-\mathrm{CaO}$ quinary slag and reduced in presence of coke using a thermogravimetric set-up. The reduced slags were further analyzed using electro-probe micro-analysis to evaluate their $\mathrm{MnO}$ and $\mathrm{SiO}_{2}$ contents. It is observed that the reduction pathway occurred in two stages: a first slow and stable stage was followed by a rapid rate increase during the second stage. The rate change shift between the two stages was found to depend on the initial charge's composition and the extent of reduction, but not on the temperature. Using an established rate equation, the kinetics of $\mathrm{MnO}$ and $\mathrm{SiO}_{2}$ reduction were modeled over the first stage. A good fit was obtained between simulated and experimental data.

https://doi.org/10.1007/s11663-020-01801-3

(C) The Author(s) 2020

\section{INTRODUCTION}

SILICOMANGANESE is produced from mixtures of Mn-sources (ores and ferromanganese slag), quartz, fluxes, reductants as well as remelts and off-grade products, all in variable amounts. In Norway, many different ores are employed as sources of manganese, each exhibiting distinct properties. ${ }^{[1]}$ As the composition of the charge has a great influence on the production of silicomanganese, a better knowledge of the ores can lead to substantial process improvements. However, silicomanganese slags are complex systems formed of many oxides, and the study of a wide range of compositions is demanding.

From the $\mathrm{MnO}-\mathrm{SiO}_{2}$ binary system to the quinary system including $\mathrm{CaO}, \mathrm{MgO}$ and $\mathrm{Al}_{2} \mathrm{O}_{3}$, various works investigated on the thermodynamics of silicate slags, often to determine the activities of the slag components. ${ }^{[2-5]}$ The thermodynamic data found experimentally was also assessed using models. ${ }^{[6]}$ Zhao and

VINCENT CANAGUIER and MERETE TANGSTAD are with the Department of Materials Science and Engineering, Norwegian University of Science and Technology, Trondheim 7491, Norway. Contact e-mail: vincent.y.canaguier@ntnu.no

Manuscript submitted on August 2, 2019.

Article published online March 9, 2020. coworkers treated the phase equilibria in a pseudo-ternary "MnO"- $(\mathrm{CaO}+\mathrm{MgO})-\left(\mathrm{SiO}_{2}+\mathrm{Al}_{2} \mathrm{O}_{3}\right)$ phase diagram, broadening from the classical $\mathrm{MnO}-\mathrm{CaO}-\mathrm{SiO}_{2}$ system. ${ }^{[7]}$ They evidenced the influence of $\mathrm{MgO}$ and $\mathrm{Al}_{2} \mathrm{O}_{3}$ on the liquidus temperatures and the primary phase fields, underlining that these oxides present in natural ores cannot be overlooked.

The distribution of manganese and silicon between slag and metal phases has been studied by equilibration. ${ }^{[8,9]}$ Ding et al. have evidenced the role of the $R$-ratio $=(\mathrm{CaO}+\mathrm{MgO}) / \mathrm{Al}_{2} \mathrm{O}_{3}$, the content of silicon in the metal increasing dramatically with increases of the $R$-ratio for a given silica content. In addition, they named temperature and silica content in the slag as key factors to reach low $\mathrm{MnO}$ content.

The reduction kinetics of $\mathrm{MnO}$ in silicate slags has been looked upon in a few studies. ${ }^{[10,11]}$ Kinetics of simultaneous $\mathrm{MnO}$ and $\mathrm{SiO}_{2}$ reduction has been investigated by Berg and Olsen. ${ }^{[12]}$ Through their work, they could not evidence a connection between $\mathrm{MnO}$ and $\mathrm{SiO}_{2}$ reduction kinetics, the reaction in Eq. [1] not being at equilibrium. Besides, they suggested that gaseous $\mathrm{SiO}$ could act as an intermediate during the reduction reaction

$$
2 \mathrm{MnO}+\mathrm{Si}=2 \mathrm{Mn}+\mathrm{SiO}_{2} .
$$

A kinetic model has been established by Ostrovski et al. to describe the reduction of $\mathrm{MnO}$ in a ferromanganese production context. ${ }^{[13]}$ The reduction reaction of $\mathrm{MnO}$, following Eq. [2], was convincingly modeled by 
Eq. [3]. There, " $A$ " is the reaction interface area, " $k$ " the reaction rate constant following the Arrhenius equation and $\left(a_{\mathrm{MnO}}-a_{\mathrm{Mn}} / K_{\mathrm{eq}}\right)$ the driving force for the reaction.

$$
\begin{gathered}
\mathrm{MnO}(1)+\mathrm{C}(\mathrm{s})=\mathrm{Mn}(1)+\mathrm{CO}(\mathrm{g}), \\
R=k \cdot A \cdot\left(a_{\mathrm{MnO}}-a_{\mathrm{Mn}} / K_{\mathrm{eq}}\right) .
\end{gathered}
$$

This kinetic model was extended to silicomanganese by $\mathrm{Kim}$ and coworkers ${ }^{[14,15]}$ to conform to silica reduction according to Eq. [4]. Next, the model, given by Eq. [5], was applied to experimental work carried out under non-isothermal conditions to estimate kinetic parameters

$$
\begin{gathered}
\mathrm{SiO}_{2}(1)+2 \mathrm{C}(\mathrm{s})=\mathrm{Si}(1)+2 \mathrm{CO}(\mathrm{g}) \\
R=k \cdot A \cdot\left(a_{\mathrm{SiO}_{2}}-a_{\mathrm{Si}} / K_{\mathrm{eq}}\right) .
\end{gathered}
$$

Recently, Jamieson et al. studied the kinetics of the silicothermic reduction of $\mathrm{MnO}$ from slags. They evidenced the preponderant role of the mass transport of $\mathrm{MnO}$ in limiting the rate. In addition, they also showed how $\mathrm{SiO}$ bubbles, formed at the slag-metal interface, can dramatically inhibit further reaction by covering most of the interface. ${ }^{[16]}$

Finally, the ore composition, beyond the $\mathrm{MnO}$ and $\mathrm{SiO}_{2}$ contents alone, contributes significantly to the reduction mechanism and kinetics. Pilot scale experiments comparing ore sources pointed out the correlation between melting temperature of the $\mathrm{Mn}$-ore and pct $\mathrm{Si}$ in the metal phase: the use of Mn-sources with low melting temperature appeared to overall decrease the pct $\mathrm{Si}$ in the metal. ${ }^{[1]}$ Essentially, improvements of industrial yields are expected by tailoring the charge to a given process.

The present aim is to find how different ore mixtures affect the reduction mechanism, to discriminate $\mathrm{MnO}$ and $\mathrm{SiO}_{2}$ reduction and to evaluate the kinetic parameters. This study addresses the isothermal reduction of three SiMn charges, using three different manganese sources. First, a thermogravimetric set-up is used to graph the mass loss during reduction. Second, the chemical composition of the remaining slag is used to evaluate the respective reduction of $\mathrm{MnO}$ and $\mathrm{SiO}_{2}$. The reduction path identified for each charge is finally used in combination with the mass loss curves to evaluate the kinetic parameters based on the models given in Eqs. [3] and [5].

\section{EXPERIMENTAL}

The present study focuses on the carbothermic reduction of silicomanganese slags under isothermal conditions. The experimental work includes the preparation of charges from industrial materials, the complete pre-reduction of high manganese oxides and iron oxides during heating $\left(\mathrm{MnO}_{2}, \mathrm{Mn}_{2} \mathrm{O}_{3}, \mathrm{Mn}_{3} \mathrm{O}_{4}\right.$ to $\mathrm{MnO}$ and $\mathrm{Fe}_{2} \mathrm{O}_{3}, \mathrm{Fe}_{3} \mathrm{O}_{4}, \mathrm{FeO}$ to $\mathrm{Fe}$ ), the isothermal reduction at high temperature and finally the analysis of the final slag composition by electron probe microanalyzer (EPMA). The procedure is analogous to what was done under non-isothermal conditions in a previous work. ${ }^{[15]}$

Three charges were prepared using manganese ores (Assmang and Comilog), high-carbon ferromanganese slag (HCS), Snekkevik quartz and Polish coke. The raw material composition and dimensions are provided in Table I. The material input was calculated to aim for 18 wt pet $\mathrm{Si}$ in the metal phase and $5 \mathrm{wt}$ pet $\mathrm{MnO}$ and 40 wt pet $\mathrm{SiO}_{2}$ in the slag phase if reaching equilibrium at $1873 \mathrm{~K}\left(1600{ }^{\circ} \mathrm{C}\right)$. The detail of the composition of the charges is given in Table II. The raw materials were initially positioned as layers in graphite crucibles (i.d. $\varnothing=30 \mathrm{~mm}$ and depth $h=61 \mathrm{~mm}$ ) ordered by melting temperature, the first to melt being placed on the top, to ensure complete mixing.

The pre-reduction and reduction reactions were carried out in a vertical graphite tube furnace. The filled graphite crucibles were suspended in the hot zone of the furnace by a Mo wire and hook, themselves hanging from a weighing balance. The atmosphere was evacuated from the furnace using a vacuum pump and was replaced by a high-purity Ar gas stream. Upon reaching $773 \mathrm{~K}\left(500{ }^{\circ} \mathrm{C}\right)$, the $\mathrm{Ar}$ stream was replaced by $\mathrm{CO}$; Ar was reintroduced upon cooling at temperatures lowering to $1173 \mathrm{~K}\left(900^{\circ} \mathrm{C}\right)$. The temperature was recorded in two locations: in the hot zone just below the crucible (B-type thermocouple) and at the furnace's wall (S-type thermocouple). The samples studied were first heated up to pre-reduction temperature, $1473 \mathrm{~K}\left(1200{ }^{\circ} \mathrm{C}\right)$, and kept there for $30 \mathrm{~min}$ utes. Next, they were rapidly heated up $\left(60^{\circ} \mathrm{C} / \mathrm{min}\right)$ to the reduction temperature in the range of $1783 \mathrm{~K}$ to $1933 \mathrm{~K}\left(1510^{\circ} \mathrm{C}\right.$ to $\left.1660{ }^{\circ} \mathrm{C}\right)$ for a chosen duration under isothermal conditions. The reduction temperatures and durations investigated for each charge are summarized in Table III.

Further in this study, experiments will be named using the aforementioned experimental parameters with the following format: (Mn-source)-(Temperature)-(Reduction duration) as e.g. Asm-1610-60.

After cooling, the crucible was casted in epoxy resin. The slag phase was mounted and polished for analysis with a JEOL JXA-8500F EPMA. For the analyses, $15 \mathrm{kV}$ acceleration voltage and a $20 \mathrm{nA}$ beam current were used. For homogeneous slag areas, the beam diameter was $2 \mu \mathrm{m}$. For non-homogeneous areas, the beam diameter was increased to $30 \mu \mathrm{m}$ to get a mean value. The samples were analyzed for $\mathrm{MnO}, \mathrm{SiO}_{2}, \mathrm{CaO}$, $\mathrm{Al}_{2} \mathrm{O}_{3}, \mathrm{MgO}, \mathrm{FeO}, \mathrm{BaO}$ and $\mathrm{SO}_{3}$. Mineral standard mounts from Astimex were used as follows: $\mathrm{Si}-\mathrm{Quartz}$, $\mathrm{Mg}$-Chlorite, S-Pyrite, Mn-Rhodonite, $\mathrm{Al}$ Plaglioclase, $\mathrm{Ca}$-Apatite, $\mathrm{Fe}$-Bustamite and $\mathrm{Ba}-$ Barite. For two-phased slags, point analysis was carried out on both phases. The volume fraction of each phase was determined based on pixel counting on back-scattered electron micrographs as well as using the measured mass losses. Examples of the microstructure observed and of a picture used for pixel counting are given in Figure 1. 
Table I. Raw Material Chemical Composition (Weight Percent) and Size

\begin{tabular}{lcccccccccccccc}
\hline Material & $\mathrm{MnO}$ & $\mathrm{MnO}_{2}$ & $\mathrm{SiO}_{2}$ & $\mathrm{Fe}_{2} \mathrm{O}_{3}$ & $\mathrm{CaO}$ & $\mathrm{MgO}$ & $\mathrm{Al}_{2} \mathrm{O}_{3}$ & $\mathrm{~S}$ & $\mathrm{C}$ & $\mathrm{CO}_{2}$ & $\mathrm{H}_{2} \mathrm{O}$ & $\mathrm{BaO}$ & $\mathrm{Total}(\mathrm{Wt} \mathrm{Pct})$ & $\mathrm{Size}(\mathrm{mm})$ \\
\hline Assmang & 31.28 & 35.50 & 6.37 & 13.66 & 6.17 & 1.08 & 0.49 & 0.14 & - & 3.1 & 0.04 & 0.45 & 98.28 & 0.5 to 1.36 \\
Comilog & 3.91 & 69.40 & 6.50 & 6.47 & 0.29 & 0.13 & 6.9 & $0.02^{*}$ & - & 0.1 & 5 & $0.21^{*}$ & 98.70 & 0.5 to \\
HCS & 35.23 & 0.00 & 24.45 & 0.00 & 18.45 & 7.53 & 12.30 & 0.46 & 0.46 & - & - & - & 98.88 \\
Quartz & 0.14 & - & 93.85 & - & 0.09 & 0.05 & 1.19 & - & - & - & - & - & 0.5 to 1.4 \\
Coke & 0.04 & - & 5.6 & 0.86 & 0.42 & 0.22 & 2.79 & - & 87.68 & - & - & 0.03 & 95.32 & 0.5 to 1.4 \\
\hline
\end{tabular}

*These measurements were carried out on a different batch of the same ore.

Table II. Composition of the Three Material Charges

\begin{tabular}{lccccrc}
\hline & \multicolumn{5}{c}{ Mass $(\mathrm{g})$} \\
\cline { 2 - 7 } Mn-Source & Assmang & Comilog & HCS & Quartz & Coke & Total \\
\hline Assmang (Asm) & 7.00 & - & - & 1.96 & 2.20 & 11.16 \\
Comilog (Com) & - & 7.00 & - & 1.71 & 2.40 & 11.11 \\
Assmang + HCS (A/HCS) & 4.00 & - & 4.00 & 1.73 & 2.50 \\
\hline
\end{tabular}

Table III. Experimental Parameters of the 27 Experiments of the Study

\begin{tabular}{|c|c|c|}
\hline Mn-Source & Temperature $\left({ }^{\circ} \mathrm{C}\right)$ & Reduction Duration (min) \\
\hline \multirow[t]{3}{*}{ Assmang (Asm) } & 1540 & $0 ; 30 ; 60 ; 120$ \\
\hline & 1610 & $0 ; 30 ; 45^{*} ; 60$ \\
\hline & 1660 & $25 ; 30$ \\
\hline \multirow[t]{3}{*}{ Comilog (Com) } & 1540 & $0 ; 30 ; 60 ; 300$ \\
\hline & 1610 & $0 ; 30 ; 60 ; 120 ; 180$ \\
\hline & 1660 & $30 ; 60$ \\
\hline \multirow[t]{3}{*}{ Assmang + HCS (A/HCS) } & 1510 & $30 ; 180$ \\
\hline & 1540 & $0 ; 15 ; 60$ \\
\hline & 1610 & 60 \\
\hline
\end{tabular}

*This experiment was carried out with 60 min pre-reduction instead of $30 \mathrm{~min}$.

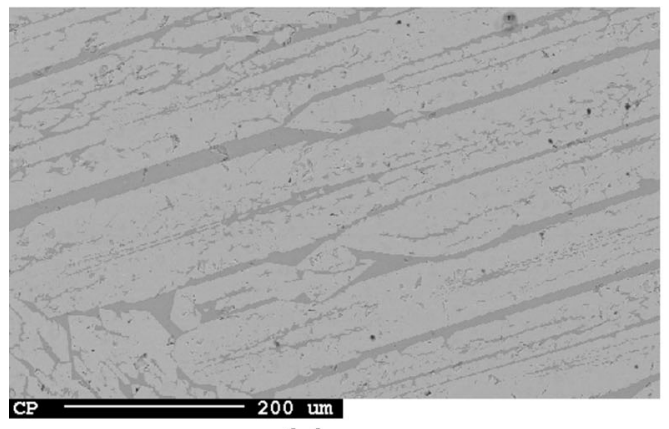

(a)

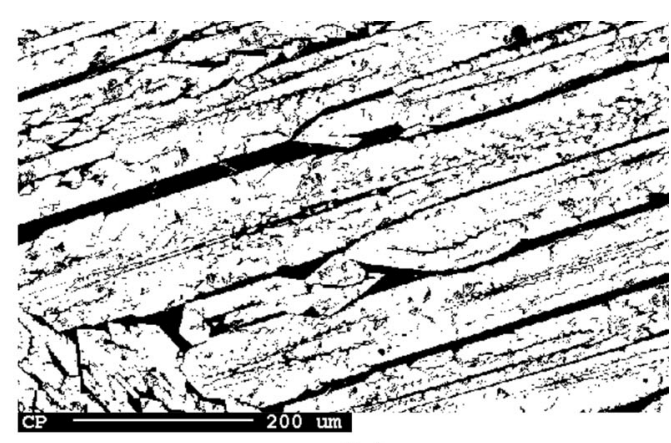

(b)

Fig. 1-Micrographs of a slag phase for Asm-1610-0: (a) back-scattered electron image and (b) black-and-white version for pixel counting.

\section{RESULTS AND DISCUSSION}

\section{A. Pre-reduction and Melting}

This study investigates the $\mathrm{MnO}$ and $\mathrm{SiO}_{2}$ slag reduction reactions, therefore, one seeks to control other potentially simultaneous processes such as pre-reduction and melting.
Maintaining the samples at a heating plateau of $1473 \mathrm{~K}\left(1200^{\circ} \mathrm{C}\right)$ for 30 minutes was found sufficient to ensure full pre-reduction. This was confirmed by experiment Asm-1610-45* for which the pre-reduction duration was doubled to 60 minutes. The isothermal section of the mass loss curves of Asm-1610-45* overlapped with that of Asm-1610-30, showing that longer 
pre-reduction had no significant effect on the subsequent reduction process. Besides, the pre-reduction stage showed excellent reproducibility as observed in Figure 2. For each type of charge, the average of the mass loss during the temperature ramp-up and pre-reduction is indicated in red, and the values within three standard deviations of the mean $(\mu \pm 3 \sigma)$ are shown in gray.

Although the chemical analyses occasionally indicated the presence of iron oxides, these were likely reduced. The measured $\mathrm{FeO}$ in pre-reduced samples is further treated as being metallic iron prills trapped within the slag phase, similarly to what was concluded in studies on ferromanganese. ${ }^{[18]}$

Concerning the melting, and despite high melting temperature of the raw materials taken separately, ${ }^{[19-21]}$ a single slag phase was consistently observed for all samples reacted for 0 minute. This indicate that complete melting was achieved prior slag reduction. This result is in agreement with what was found in earlier works. ${ }^{[14]}$

\section{B. Isothermal Reduction}

The isothermal reduction mass loss curves for the three charges considered are given in Figure 3. On the graphs, each line is associated to one experiment and its end-state is indicated by a marker. The end-state mass loss is also reported in Table IV. The mass loss during reduction is defined as the mass loss during the isothermal stage, minus the pre-reduction mass loss from the experiments of reference $(0$ minute of reduction). Note that the reduction mass loss in Figure 3 and Table IV comprises the loss of carbon, oxygen leaving the system as $\mathrm{CO}$ gas.

The reduction mass loss curves obtained at similar experimental conditions overlapped remarkably. The good fit between these illustrated the reproducibility of the experimental work. Only Asm-1610-60, represented with a dashed line in Figure 3, differed notably with similar experiments and was further considered as an outlier.

From the mass loss curves, one should notice the existence of two stages during the isothermal reduction, the transition between these two stages being marked by a rapid increase of the mass loss rate. This transition shift between slow and fast reduction, the rate change shift, is indicated by a dashed line: it is well defined for Assmang and Comilog charges but can only be conjectured for Assmang + HCS. The rate change shift was quicker at higher temperatures and happened earlier in time, however, it appeared to be constant relative to mass loss for a given charge. Thus, the shift could be linked to chemical and/or physical properties of the slag in this range. Foaming, which was observed occasionally, could be linked to the rate increase. However, the lack of knowledge on this process made it impossible to conclude whether it was a cause or a consequence of the rate increase, or even in relation with it. Thus, foaming was not addressed in this work.

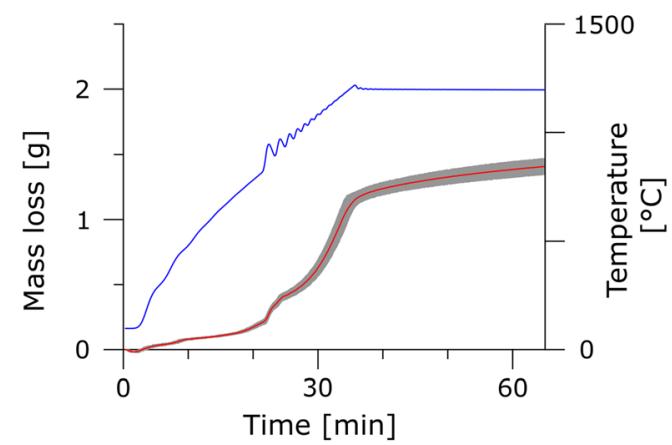

(a)

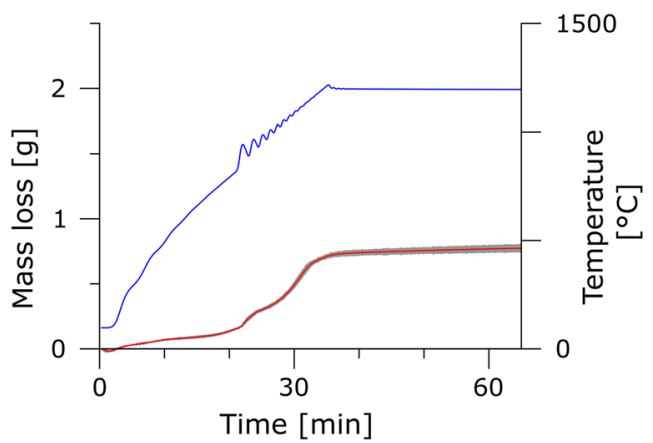

(c)

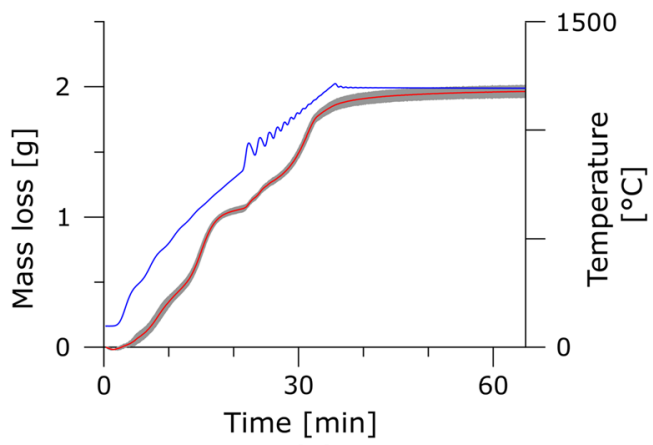

(b)

Fig. 2-Average of the mass loss during pre-reduction (in red) and of the crucible temperature (in blue) for (a) Assmang charge, (b) Comilog charge, (c) Assmang + HCS charge. The gray domains correspond to the values within three standard deviations of the mean $(\mu \pm 3 \sigma)$. 


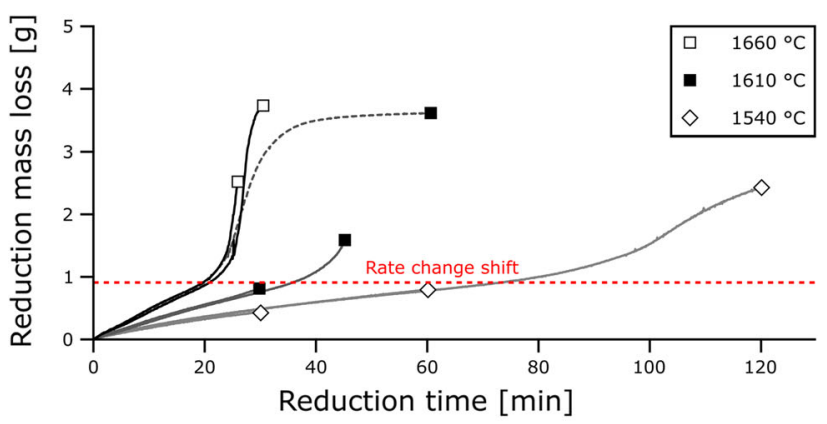

(a)

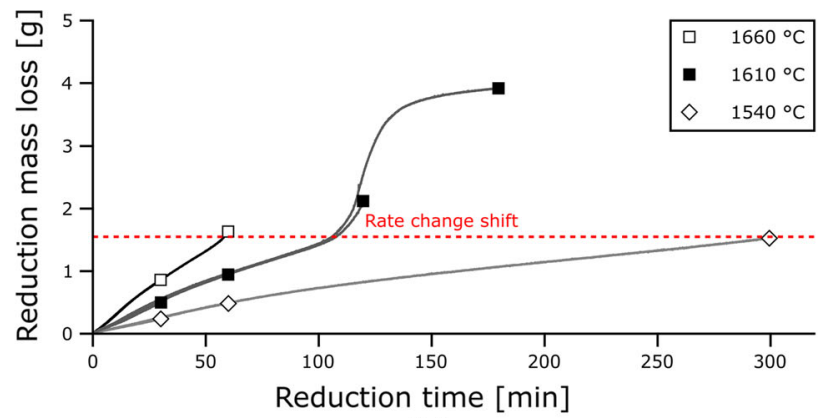

(b)

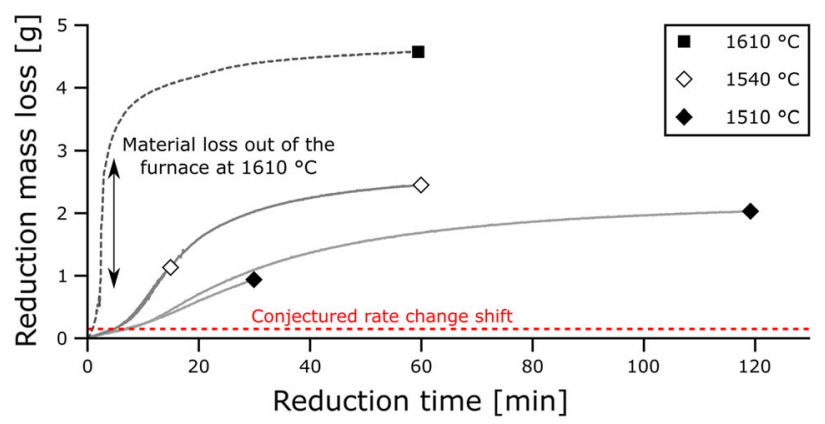

(c)

Fig. 3-Reduction mass loss curves for (a) Assmang charge, (b) Comilog charge, (c) Assmang + HCS charge. Outlier curves Asm-1610-60 and A/HCS-1610-60 are shown with a dashed line.

The temperature of the isothermal stage had a significant influence on the reaction rate and on the extent of reduction. Temperature increases between $1813 \mathrm{~K}$ and $1933 \mathrm{~K}\left(1540{ }^{\circ} \mathrm{C}\right.$ and $\left.1660{ }^{\circ} \mathrm{C}\right)$ for Assmang and Comilog charges, and $1783 \mathrm{~K}$ to $1883 \mathrm{~K}\left(1510^{\circ} \mathrm{C}\right.$ to $1610^{\circ} \mathrm{C}$ ) for the Assmang $+\mathrm{HCS}$ charge consistently led to increases of the mass loss rate. This directly translates to a loss of oxygen in the form of $\mathrm{CO}$ gas due to reduction of the slag. The extent of reduction was also increased with an increase of temperature, as can be observed for Assmang and Assmang + HCS series. Note that the measured mass loss for experiment $\mathrm{A} /$ HCS-1610-60 is skewed due to material losses, the slag falling from the crucible after foaming.

\section{Slag Analysis}

The compositions of the slag phase after reduction investigated by EPMA are presented in Table V. It was considered that during pre-reduction, all the iron and manganese oxides reduced to metallic iron and $\mathrm{MnO}$, respectively. The concentrations of $\mathrm{BaO}, \mathrm{FeO}$, and $\mathrm{SO}_{3}$ being consistently lower than 1 pct, they were not reported in the table.

Assuming unreducible oxides remain in the slag phase, the contents of $\mathrm{MgO}, \mathrm{Al}_{2} \mathrm{O}_{3}$ and $\mathrm{CaO}$ were used to evaluate the mass of slag reduced. Together with the mass losses from Table IV, the amounts of $\mathrm{MnO}$ and $\mathrm{SiO}_{2}$ reduced after each experiment were plotted in Figure 4. For each charge, the obtained data points formed a curve. Trend lines were drawn to illustrate these reduction paths, i.e., the composition changes during reduction.

Although the three charges differed in terms of chemistry, the reduction paths were similar. The reduction of $\mathrm{MnO}$ and $\mathrm{SiO}_{2}$ happened simultaneously at all experimental conditions. At the start of the reduction, mostly $\mathrm{Mn}$ was produced while only little $\mathrm{Si}$ was obtained, particularly for the Ass/HCS charge. As indicated by the trend lines of Figure 4, there was a steady increase of the $\mathrm{Si} / \mathrm{Mn}$ ratio in the newly produced metal as the reduction progressed.

The existence of such reduction paths having little to no dependence on temperature could indicate that $\mathrm{MnO}$ and $\mathrm{SiO}_{2}$ reduction processes are linked. Previous works suggested a connection between $\mathrm{MnO}$ and $\mathrm{SiO}_{2}$ through Eq. 1, ${ }^{[22]}$ the slag-metal equilibrium reaction, presumed to be faster than reduction reactions. However, Berg and Olsen did not evidence this mechanism in their work.${ }^{[12]}$ For the current study, the slag-metal equilibrium curves at $1883 \mathrm{~K}\left(1610^{\circ} \mathrm{C}\right)$, which were calculated using FactSage 7.1, contrasted with the reduction path determined experimentally as shown in Figure 4. This indicates that the slag-metal reaction was not at equilibrium, although it may be taking place, the experimental data exhibiting a higher $\mathrm{Mn} / \mathrm{Si}$ ratio in the produced metal compared to the slag-metal equilibrium.

Although the trend lines drawn in Figure 4 do not represent slag-metal equilibrium, they still indicate a relationship between $\mathrm{MnO}$ and $\mathrm{SiO}_{2}$ reduction, with temperature not affecting the reduction path. In fact, the use of the trend line constrains the temperature dependence of the reduction reactions: the overall mass loss is determined by temperature, while the disparity between $\mathrm{MnO}$ and $\mathrm{SiO}_{2}$ reduction is decided by the driving force.

The composition of the slag at the rate shift was determined using the reduction path curves. The shift was thus determined to occur at $47 \mathrm{wt}$ pet $\mathrm{MnO}$ and 41 wt pet $\mathrm{SiO}_{2}$ for Asm, at 42 wt pet $\mathrm{MnO}$ and 44 wt pet $\mathrm{SiO}_{2}$ for $\mathrm{Com}$ and at 48 wt pet $\mathrm{MnO}$ and 35 wt pet $\mathrm{SiO}_{2}$ for $\mathrm{A} / \mathrm{HCS}$. 
Table IV. Starting Mass, Total Mass Loss and Mass Loss During Reduction for Each Experiment

\begin{tabular}{lccc}
\hline Experiment & $\begin{array}{c}\text { Starting } \\
\text { Mass }(\mathrm{g})\end{array}$ & $\begin{array}{c}\text { Mass } \\
\text { Loss }(\mathrm{g})\end{array}$ & $\begin{array}{c}\text { Reduction Mass } \\
\text { Loss }(\mathrm{g})\end{array}$ \\
\hline Asm-1540-0 & 11.16 & 1.54 & 0.00 \\
Asm-1540-30 & & 1.97 & 0.43 \\
Asm-1540-60 & & 2.33 & 0.79 \\
Asm-1540-120 & & 3.97 & 2.43 \\
Asm-1610-0 & & 1.58 & 0.00 \\
Asm-1610-30 & & 2.40 & 0.82 \\
Asm-1610-45* & & 3.17 & 1.59 \\
Asm-1610-60 & & 5.20 & 3.62 \\
Asm-1660-25 & & 4.11 & 2.54 \\
Asm-1660-30 & & 5.33 & 3.75 \\
Com-1540-0 & 11.11 & 2.04 & 0.00 \\
Com-1540-30 & & 2.24 & 0.20 \\
Com-1540-60 & & 2.53 & 0.49 \\
Com-1540-300 & & 3.51 & 1.47 \\
Com-1610-0 & & 2.06 & 0.00 \\
Com-1610-30 & & 2.52 & 0.46 \\
Com-1610-60 & & 2.98 & 0.92 \\
Com-1610-120 & & 4.18 & 2.12 \\
Com-1610-180 & & 5.95 & 3.89 \\
Com-1660-30 & & 2.94 & 0.88 \\
Com-1660-60 & & 3.72 & 1.66 \\
A/HCS-1510-30 & 12.23 & 1.79 & 0.93 \\
A/HCS-1510-120 & & 2.89 & 2.03 \\
A/HCS-1540-0 & & 0.86 & 0.00 \\
A/HCS-1540-15 & & 2.02 & 1.16 \\
A/HCS-1540-60 & & 3.33 & 2.47 \\
A/HCS-1610-60 & & 5.58 & 4.72 \\
\hline
\end{tabular}

The samples reacted for 0 min are used as reference to calculate the mass loss from reduction.

\section{Reaction Kinetics, Modeling and Analysis}

The rate models given in Eqs. 3 and 5 were used to study the reaction kinetics in the first reduction step, before the rapid increase of reduction rate. These rate models were studied previously for $\mathrm{SiMn}^{[15]}$ and FeMn production. ${ }^{[13]}$ The activities in the slag and metal phases were calculated using FactSage 7.1 for each composition along the reduction paths of Figure 4. For the slag phase, the FToxid database was used, and activities of $\mathrm{SiO}_{2}$ and $\mathrm{MnO}$ were calculated considering a slag containing $\mathrm{SiO}_{2}, \mathrm{MgO}, \mathrm{MnO}, \mathrm{Al}_{2} \mathrm{O}_{3}$ and $\mathrm{CaO}$. For the metal phase, a carbon saturated mixture of $\mathrm{Fe}$, $\mathrm{Mn}$ and Si was considered, and the FSstel database was used. Next, the driving forces for both reactions were deduced from the calculated activities and the equilibrium constants at each temperature.

The changes in the reaction driving forces in Eqs. 2 and 4 caused the increase of the $\mathrm{Si} / \mathrm{Mn}$ ratio during reduction. This was confirmed by the changes in the activities calculated along the reduction paths. Figure 5 shows the activities of $\mathrm{MnO}$ and $\mathrm{SiO}_{2}$ for the Assmang charge during reduction as well as the activities of $\mathrm{Mn}$ and $\mathrm{Si}$ in the metal phase. The quick impoverishment of $\mathrm{MnO}$ in the slag due to reduction led to a decline of the activity of $\mathrm{MnO}$ together with a jump of the activity of $\mathrm{SiO}_{2}$.
Table V. Experimental Results from EPMA

\begin{tabular}{lrrrrr}
\hline & \multicolumn{5}{c}{ Slag Composition (Wt Pct) } \\
\cline { 2 - 6 } Experiment & $\mathrm{SiO}_{2}$ & $\mathrm{MgO}$ & $\mathrm{MnO}$ & $\mathrm{Al}_{2} \mathrm{O}_{3}$ & $\mathrm{CaO}$ \\
\hline Asm-1540-0 & 33.89 & 1.39 & 57.24 & 0.81 & 6.57 \\
Asm-1540-30 & 38.15 & 1.35 & 51.65 & 0.98 & 7.86 \\
Asm-1540-60 & 38.95 & 1.76 & 49.48 & 1.00 & 8.81 \\
Asm-1540-120 & 49.76 & 2.86 & 29.86 & 3.32 & 14.19 \\
Asm-1610-0 & 33.62 & 1.49 & 57.49 & 0.75 & 6.64 \\
Asm-1610-30 & 40.81 & 1.50 & 47.34 & 1.15 & 9.20 \\
Asm-1610-45* & 47.84 & 2.31 & 37.91 & 1.96 & 9.98 \\
Asm-1610-60 & 41.11 & 7.18 & 2.99 & 9.00 & 39.71 \\
Asm-1660-25 & 53.15 & 3.75 & 19.84 & 3.93 & 19.32 \\
Asm-1660-30 & 49.71 & 6.96 & 6.20 & 6.17 & 30.96 \\
Com-1540-0 & 30.31 & 0.15 & 60.59 & 8.73 & 0.22 \\
Com-1540-30 & 31.68 & 0.18 & 58.60 & 9.28 & 0.25 \\
Com-1540-60 & 34.45 & 0.18 & 54.96 & 10.14 & 0.27 \\
Com-1540-300 & 40.94 & 0.33 & 46.64 & 11.84 & 0.46 \\
Com-1610-0 & 30.92 & 0.17 & 61.63 & 7.06 & 0.23 \\
Com-1610-30 & 35.78 & 0.23 & 55.25 & 8.49 & 0.25 \\
Com-1610-60 & 37.43 & 0.31 & 51.13 & 10.88 & 0.25 \\
Com-1610-120 & 47.99 & 0.48 & 34.21 & 16.79 & 0.52 \\
Com-1610-180 & 30.18 & 3.22 & 5.25 & 55.37 & 5.97 \\
Com-1660-30 & 37.54 & 0.27 & 52.34 & 9.41 & 0.45 \\
Com-1660-60 & 44.00 & 0.37 & 42.29 & 12.91 & 0.43 \\
A/HCS-1510-30 & 41.17 & 1.42 & 38.65 & 5.48 & 13.37 \\
A/HCS-1510-120 & 47.93 & 1.96 & 23.80 & 7.82 & 18.48 \\
A/HCS-1540-0 & 34.02 & 1.33 & 49.63 & 4.32 & 10.71 \\
A/HCS-1540-15 & 44.06 & 1.57 & 33.18 & 6.25 & 14.94 \\
A/HCS-1540-60 & 49.28 & 2.38 & 17.77 & 8.94 & 21.62 \\
A/HCS-1610-60 & 43.48 & 3.59 & 5.19 & 13.99 & 33.75 \\
\hline \multicolumn{1}{c}{ The sum of all oxides is normalized to $100 \mathrm{wt}$ pct. } & \\
\hline & & & & &
\end{tabular}

The changes of the driving force did not affect the overall rate significantly during the first stage of reduction, as seen from the initial stable reduction rate for Assmang and Comilog charges. In addition, assuming a constant reaction interface and neglecting the decrease of $a_{\mathrm{MnO}}$, the increase of $a_{\mathrm{SiO}_{2}}$ alone cannot justify the sudden rate increase observed.

The time dependency was added in the model using recorded mass loss measurements during slag reduction from the thermogravimetric set-up. The good reproducibility of the experimental work permitted the use of the longest curve only for each couple of temperature and charge. Experiment Asm-1610-60 is replaced by Asm-1610-45* as the former was considered being an outlier.

Finally, the reaction surface area was calculated assuming that the slag is a shrinking cylinder of revolution whose half the surface is in contact with carbon reductants. This assumption was based on the visual observations of the slag during reduction as shown in Figure 6. The slag cylinders were considered to keep their ratio of height to radius during the reduction, which was chosen equal to $2 / 3$ based on the picture in Figure 6. As the mass loss is known, the mass of the slag left is known. Its density was assumed to be constant and equal to $3000 \mathrm{~kg} / \mathrm{m}^{3}$ in all cases and thus the volume and surface area of the slag can be calculated. The 


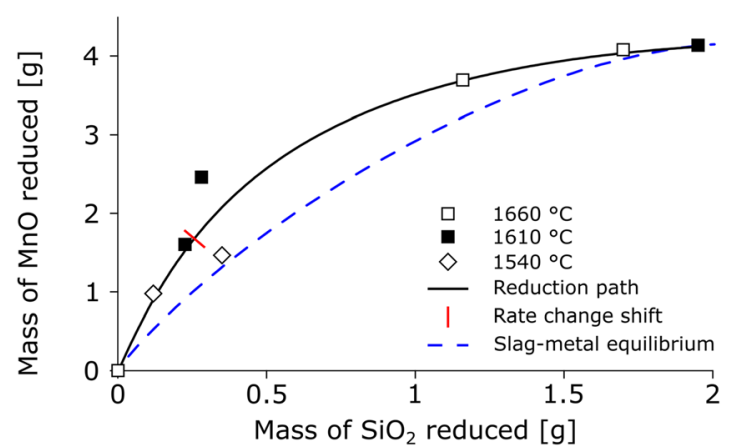

(a)

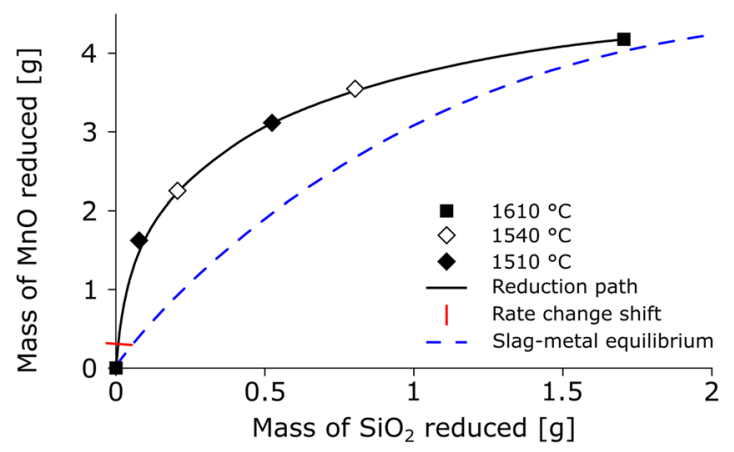

(c)

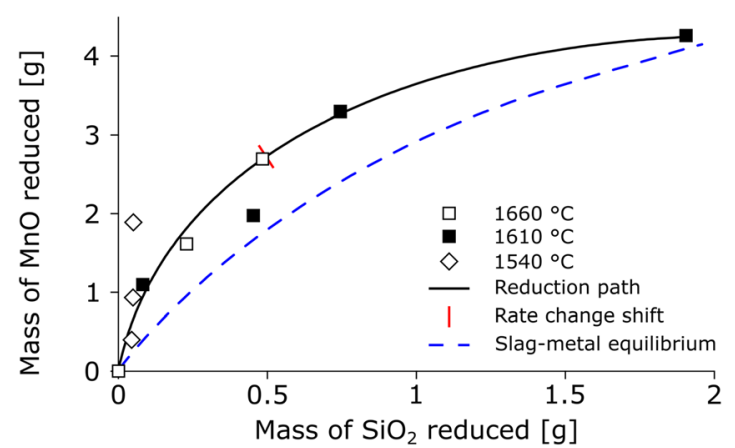

(b)

Fig. 4-Reduced $\mathrm{MnO}$ and $\mathrm{SiO}_{2}$ for (a) Assmang experiments, (b) Comilog experiments, (c) Assmang + HCS experiments. The slag-metal equilibrium lines (blue-dashed lines) were calculated at $1883 \mathrm{~K}\left(1610^{\circ} \mathrm{C}\right)$.

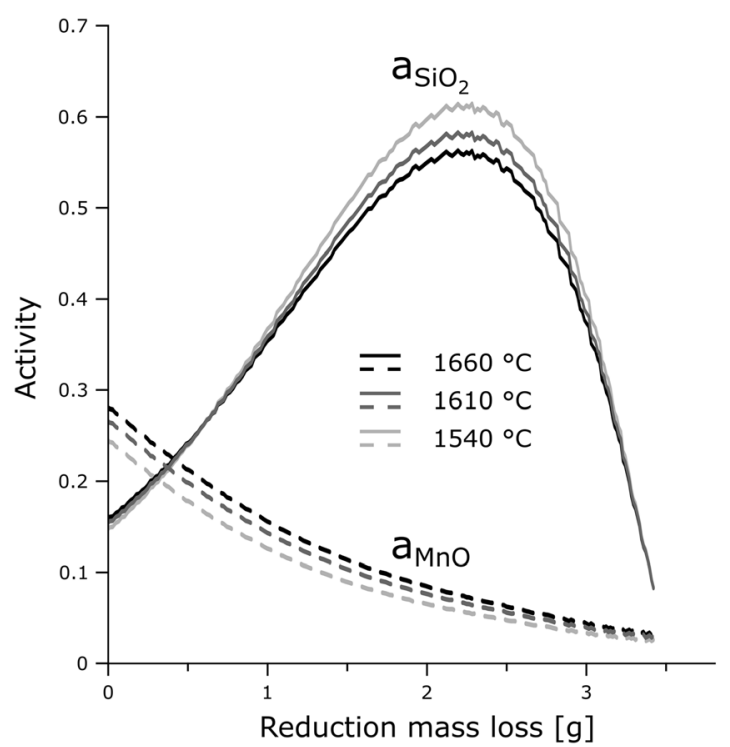

(a)

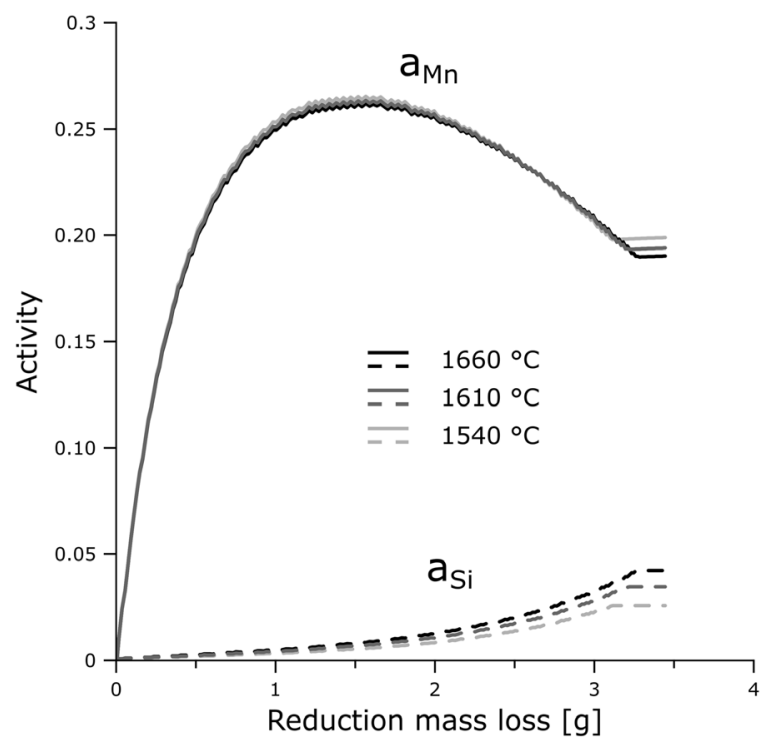

(b)

Fig. 5-Activities along the reduction path for the Assmang charge at $1813 \mathrm{~K}, 1883 \mathrm{~K}$, and $1933 \mathrm{~K}\left(1540{ }^{\circ} \mathrm{C}, 1610^{\circ} \mathrm{C}\right.$, and $\left.1660{ }^{\circ} \mathrm{C}\right)$ calculated using FactSage $7.1(a)$ in the slag phase and $(b)$ in the metal phase.

approach used here contrasts with that of Ostrovski et $a l^{[13]}$ and Kim et al. ${ }^{[15]}$ who considered the reaction surface to be governed by the shrinking coke particles' surface area. As there was no clear penetration of the coke particles within the slag phase, this approach was not retained. 


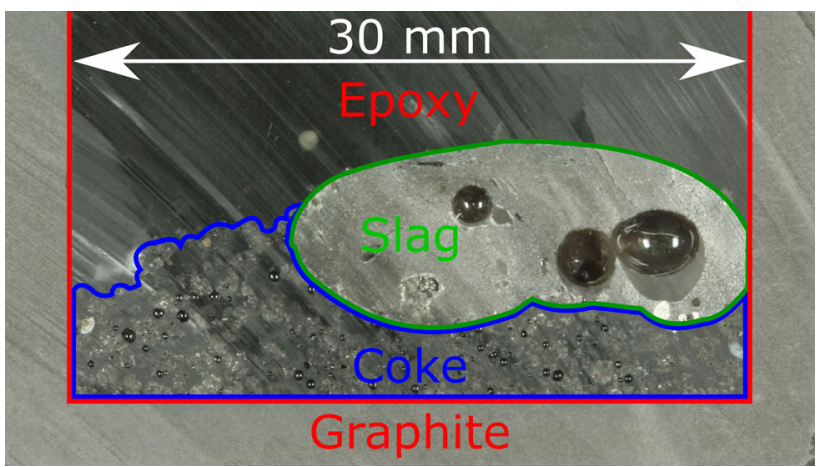

Fig. 6-Cross-section view of the crucible of Asm-1600-0. The slag phase rests on the coke layer.

The rate constants $k_{\mathrm{MnO}}$ and $k_{\mathrm{SiO}_{2}}$, respectively for $\mathrm{MnO}$ and $\mathrm{SiO}_{2}$ reduction reactions, were calculated at each step along the reduction path. Figure 7 shows an example of the calculated rate constant values for Asm-1610-45* as a function of time. The rapid increase of the rate constants marks the rate change shift, and hence the limit of the current model's validity. The average rate constants are indicated as a blue-dashed bar in Figure 7, the length of the bar indicating the range over which it was calculated.

The rate constants $k_{\mathrm{MnO}}$ and $k_{\mathrm{SiO}_{2}}$ used for calculations were taken as the average of the rate constants in the stable domain prior the rate change. The apparent activation energies $E_{\mathrm{a}, \mathrm{MnO}}$ and $E_{\mathrm{a}, \mathrm{SiO}_{2}}$, were calculated by graphing $\ln \left(k_{\mathrm{MnO}}\right)$ and $\ln \left(k_{\mathrm{SiO}_{2}}\right)$ vs $1 / T$ for each charge in accordance with the Arrhenius law.

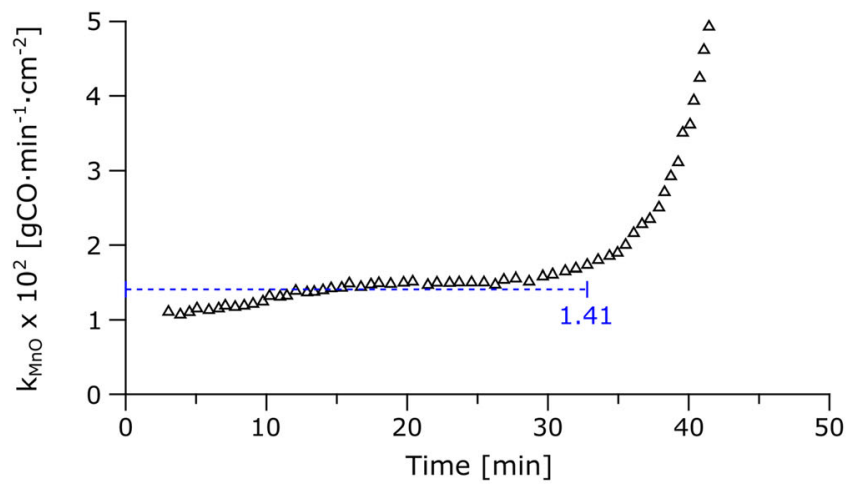

(a)
Table VI. Apparent Activation Energies for $\mathrm{MnO}$ and $\mathrm{SiO}_{2}$ Reduction

\begin{tabular}{lcc}
\hline Charge & $E_{\mathrm{a}, \mathrm{MnO}}(\mathrm{kJ} / \mathrm{mol})$ & $E_{\mathrm{a}, \mathrm{SiO}_{2}}(\mathrm{~kJ} / \mathrm{mol})$ \\
\hline Asm & 185 & 230 \\
Com & 210 & 340 \\
A/HCS & 325 & 380 \\
\hline
\end{tabular}

In the present study, the apparent activation energy for $\mathrm{SiO}_{2}$ reduction was consistently higher than that for $\mathrm{MnO}$ reduction. Besides, the choice of raw materials directly affected those activation energies: for both $\mathrm{MnO}$ and $\mathrm{SiO}_{2}$ reduction, the Asm charge exhibited the smallest energies, followed by Com and A/HCS. Thus, the present results for Asm and $\mathrm{A} / \mathrm{HCS}$ contrast with the non-isothermal work from Kim et al. ${ }^{[15]}$ albeit a similar set-up and charge, as his model included both the slow and high reduction stage. Based on the activation energies of Table VI, the model was confronted to the experimental data as graphed in Figure 8. A good fit was obtained prior the rate change shift. The frequency factors of the rate constants used for modeling, $k_{0, \mathrm{MnO}}$ and $k_{0, \mathrm{SiO}_{2}}$, are given in Table VII. The modeled rate constants of $\mathrm{MnO}$ and $\mathrm{SiO}_{2}$ reduction are plotted as a function of temperature in Figure 9. It appears that the rate of $\mathrm{MnO}$ reduction is always higher than that of $\mathrm{SiO}_{2}$, but the magnitude of the difference varies with the charge used. For the charge A/HCS in particular, the rate of $\mathrm{MnO}$ reduction is much higher than that of $\mathrm{SiO}_{2}$ reduction.

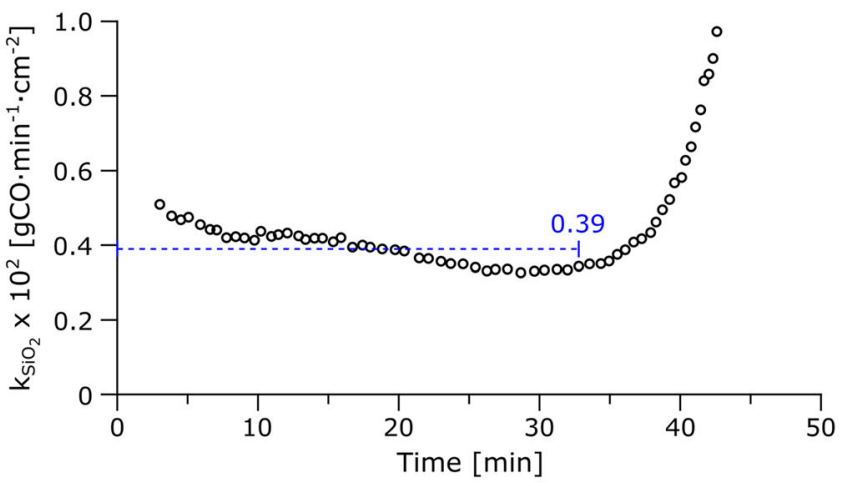

(b)

Fig. 7- Calculated rate constants as a function of time for (a) $\mathrm{MnO}$ (triangles) and (b) $\mathrm{SiO}_{2}$ (circles) during the reduction of Asm-1610-45*. 


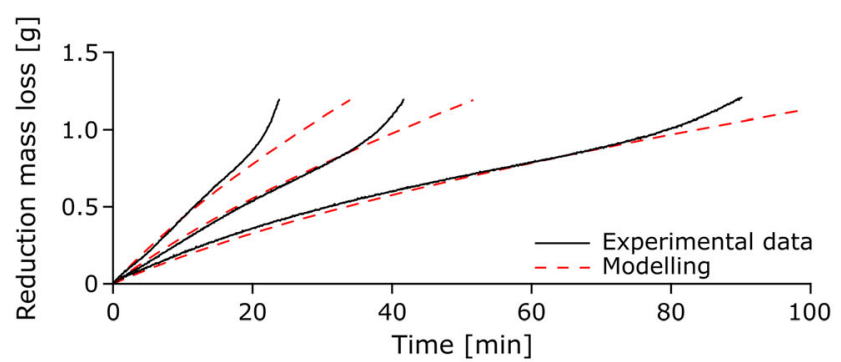

(a)

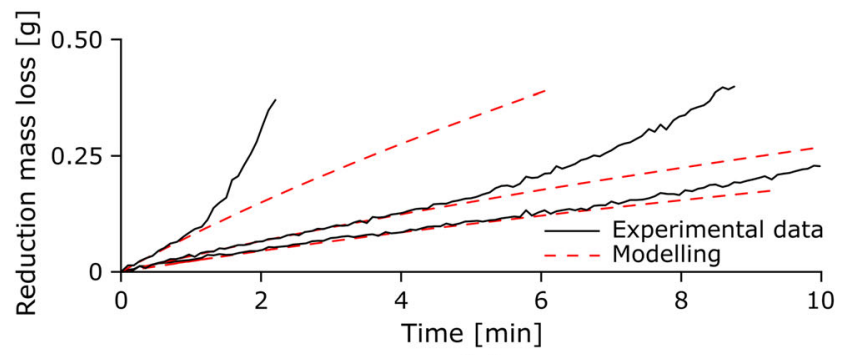

(c)

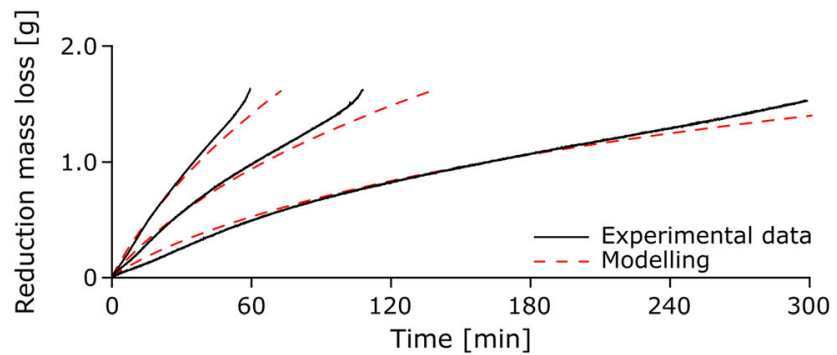

(b)

Fig. 8-Experimental data and modeled curve for the reduction mass loss for (a) Assmang charge, (b) Comilog charge, $(c)$ Assmang + HCS charge.

Table VII. Frequency Factor for $\mathrm{MnO}$ and $\mathrm{SiO}_{2}$ Reduction Reaction

\begin{tabular}{lcc}
\hline Charge & $k_{0, \mathrm{MnO}}\left(\mathrm{gCO} / \mathrm{min} / \mathrm{cm}^{2}\right)$ & $k_{0, \mathrm{SiO}_{2}}\left(\mathrm{gCO} / \mathrm{min} / \mathrm{cm}^{2}\right)$ \\
\hline Asm & $1.8 \times 10^{3}$ & $9.7 \times 10^{3}$ \\
Com & $7.3 \times 10^{3}$ & $4.4 \times 10^{6}$ \\
A/HCS & $3.5 \times 10^{7}$ & $8.5 \times 10^{7}$ \\
\hline
\end{tabular}

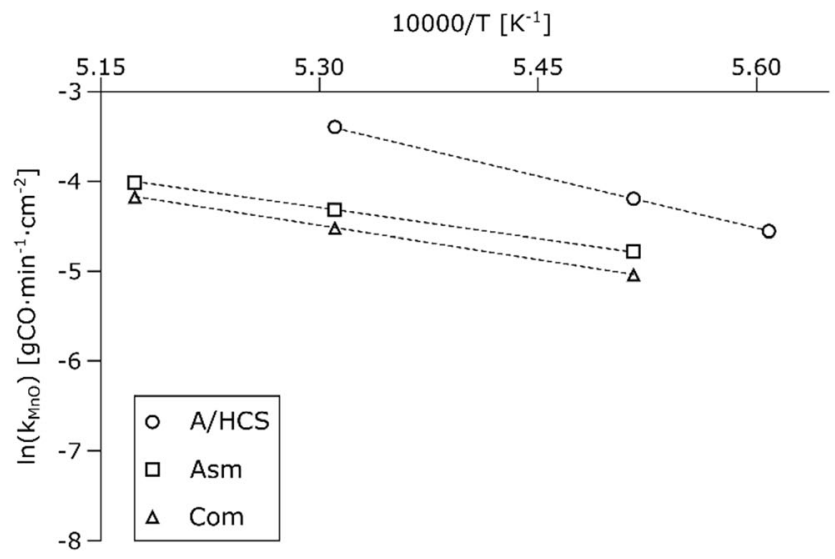

(a)
The model employed started to deviate from the experimental data when the reaction rate increased abruptly at the rate change shift. This correlates with the steep increase of the calculated rate constants observed in Figure 7. However, the rate constants are not the origin of this change, nor are the changes of the driving force. The simultaneous increase of both reduction processes could be due to an increase of the reaction interface not factored in the model.

Fig. 9- Rate constant as a function of temperature for (a) $\mathrm{MnO}$ reduction and (b) $\mathrm{SiO}_{2}$ reduction. 


\section{CONCLUSIONS}

Silicomanganese is a high-quality alloy vital for the steelmaking industry. To prepare for variations in the raw material supply for its production, research work is conducted to assess the behavior of three charge types during slag reduction.

The reduction of the slag charges was a two-step mechanism. The reduction was initially stable and the rate constant until a sudden increase of the rate marking the change to a second stage. During this phase, the rate rapidly peaked and subsequently decreased towards the end of the reduction.

The conditions for the rate shift were found independent of temperature but a function of the mass loss, hence of the slag composition. The shift was observed at 47 wt pet $\mathrm{MnO}$ and 41 wt pet $\mathrm{SiO}_{2}$ for the Asm charge, 42 wt pet $\mathrm{MnO}$ and 44 wt pet $\mathrm{SiO}_{2}$ for the Com charge and $48 \mathrm{wt}$ pet $\mathrm{MnO}$ and 35 wt pet $\mathrm{SiO}_{2}$ for the A/HCS charge.

The reduction kinetics were handily modeled for the first stage of reduction. Based on the measured mass losses and the chemical analysis of the slag, the activity and hence the driving force for reduction were obtained. The reaction interface was estimated considering no penetration of the slag within the coke layer, as observed.

The kinetic parameters $k_{0}$ and $E_{\mathrm{a}}$ were determined for $\mathrm{MnO}$ and $\mathrm{SiO}_{2}$ reduction during the stable initial stage. Disparities were found between the manganese sources: the reduction of $\mathrm{MnO}$ and $\mathrm{SiO}_{2}$ from the Asm charge was faster than for the Com charge. The A/HCS charge was significantly faster concerning $\mathrm{MnO}$ reduction, but one must bear in mind the modest extent of the first stage for this charge.

\section{ACKNOWLEDGMENTS}

Open Access funding provided by NTNU Norwegian University of Science and Technology (incl St. Olavs Hospital - Trondheim University Hospital). This publication has been funded by the SFI Metal Production, (Centre for Research-based Innovation, 237738). The authors gratefully acknowledge the financial support from the Research Council of Norway and the partners of the SFI Metal Production.

\section{OPEN ACCESS}

This article is licensed under a Creative Commons Attribution 4.0 International License, which permits use, sharing, adaptation, distribution and reproduction in any medium or format, as long as you give appro- priate credit to the original author(s) and the source, provide a link to the Creative Commons licence, and indicate if changes were made. The images or other third party material in this article are included in the article's Creative Commons licence, unless indicated otherwise in a credit line to the material. If material is not included in the article's Creative Commons licence and your intended use is not permitted by statutory regulation or exceeds the permitted use, you will need to obtain permission directly from the copyright holder. To view a copy of this licence, visit http://creativec ommons.org/licenses/by/4.0/.

\section{REFERENCES}

1. M. Tangstad, P. Calvert, H. Brun, and A.G. Lindseth: Int. Ferro-Alloys Congr., 10th, 2004, pp. 213-22.

2. K.P. Abraham, M.W. Davies, and F.D. Richardson: J. Iron Steel Inst. Lond., 1960, vol. 196, pp. 82-89.

3. S.R. Mehta and F.D. Richardson: J. Iron Steel Inst. Lond., 1965, vol. 203, pp. 524-28.

4. B.K.D.P. Rao and D.D.R. Gaskell: Metall. Trans. B, 1981, vol. 12B, pp. 311-17.

5. H. Ohta and H. Suito: Metall. Mater. Trans. B, 1996, vol. 27B, pp. 943-53.

6. Y.-B. Kang, I.-H. Jung, S.A. Decterov, A.D. Pelton, and H.-G. Lee: ISIJ Int., 2004, vol. 44, pp. 965-74.

7. B. Zhao, E. Jak, and P.C. Hayes: ISIJ Int., 2005, vol. 45, pp. 101926.

8. H. Cengizler and R.H. Eric: Int. Conf. Molten Slags, Fluxes Salts, 10th, 2016, pp. 1309-17.

9. W. Ding and S.E. Olsen: ISIJ Int., 2000, vol. 40, pp. 850-56.

10. T.-A. Skjervheim and S.E. Olsen: Int. Ferro-Alloys Congr., 7th, 1995, pp. 631-39.

11. V. Olsø, M. Tangstad, and S.E. Olsen: Int. Ferro-Alloys Congr., 8th, 1998, pp. 279-83.

12. K. Berg and S.E. Olsen: Report STF24 A04531, SINTEF, Trondheim, 2004

13. O. Ostrovski, S.E. Olsen, M. Tangstad, and M. Yastreboff: Can. Metall. $Q ., 2002$, vol. 41, pp. 309-18.

14. P.P. Kim: Ph.D. Thesis, Norwegian University of Science and Technology, Trondheim, Norway, 2018.

15. P.P. Kim and M. Tangstad: Metall. Mater. Trans. B, 2018, vol. 49B, pp. 1185-96.

16. B. Jamieson, Y. Tabatabaei, M. Barati, and K. Coley: Metall. Mater. Trans. B, 2019, vol. 50B, pp. 192-203.

17. E. Ringdalen and M. Tangstad: Int. Ferro-Alloys Congr., 13rd, 2013, pp. 197-206.

18. G. Tranell, S. Gaal, D. Lu, M. Tangstad, and J. Safarian: Int. Ferro-Alloys Congr., 11th, 2007, pp. 231-40.

19. S. Gaal, D. Lou, S. Wasbø, B. Ravary, and M. Tangstad: Int. Ferro-Alloys Congr., 11th, 2007, pp. 247-57.

20. E. Ringdalen, S. Gaal, M. Tangstad, and O. Ostrovski: Metall. Mater. Trans. B, 2010, vol. 41B, pp. 1220-29.

21. E. Ringdalen and M. Tangstad: Int. Conf. Molten Slags, Fluxes Salts, 10th, 2016, pp. 43-51.

22. S.E. Olsen, M. Tangstad, and T. Lindstad: Production of Manganese Ferroalloys, Tapir Akademisk Forlag, Trondheim, 2007, pp. $182-83$.

Publisher's Note Springer Nature remains neutral with regard to jurisdictional claims in published maps and institutional affiliations. 